\title{
Correction to: C11 orf95-RELA reprograms 3D epigenome in supratentorial ependymoma
}

\author{
Jacqueline Jufen Zhu ${ }^{1}$. Nathaniel Jillette ${ }^{1} \cdot$ Xiao-Nan $\mathrm{Li}^{2,3} \cdot$ Albert Wu Cheng ${ }^{1,4,5,6} \cdot$ Ching C. Lau $^{1,4,7,8}$ (D)
}

Published online: 23 October 2020

๑) Springer-Verlag GmbH Germany, part of Springer Nature 2020

\section{Correction to: Acta Neuropathologica} https://doi.org/10.1007/s00401-020-02225-8

In the original publication, Fig. 1 was incorrectly published with same two histograms at the bottom. The corrected Fig. 1 given here.
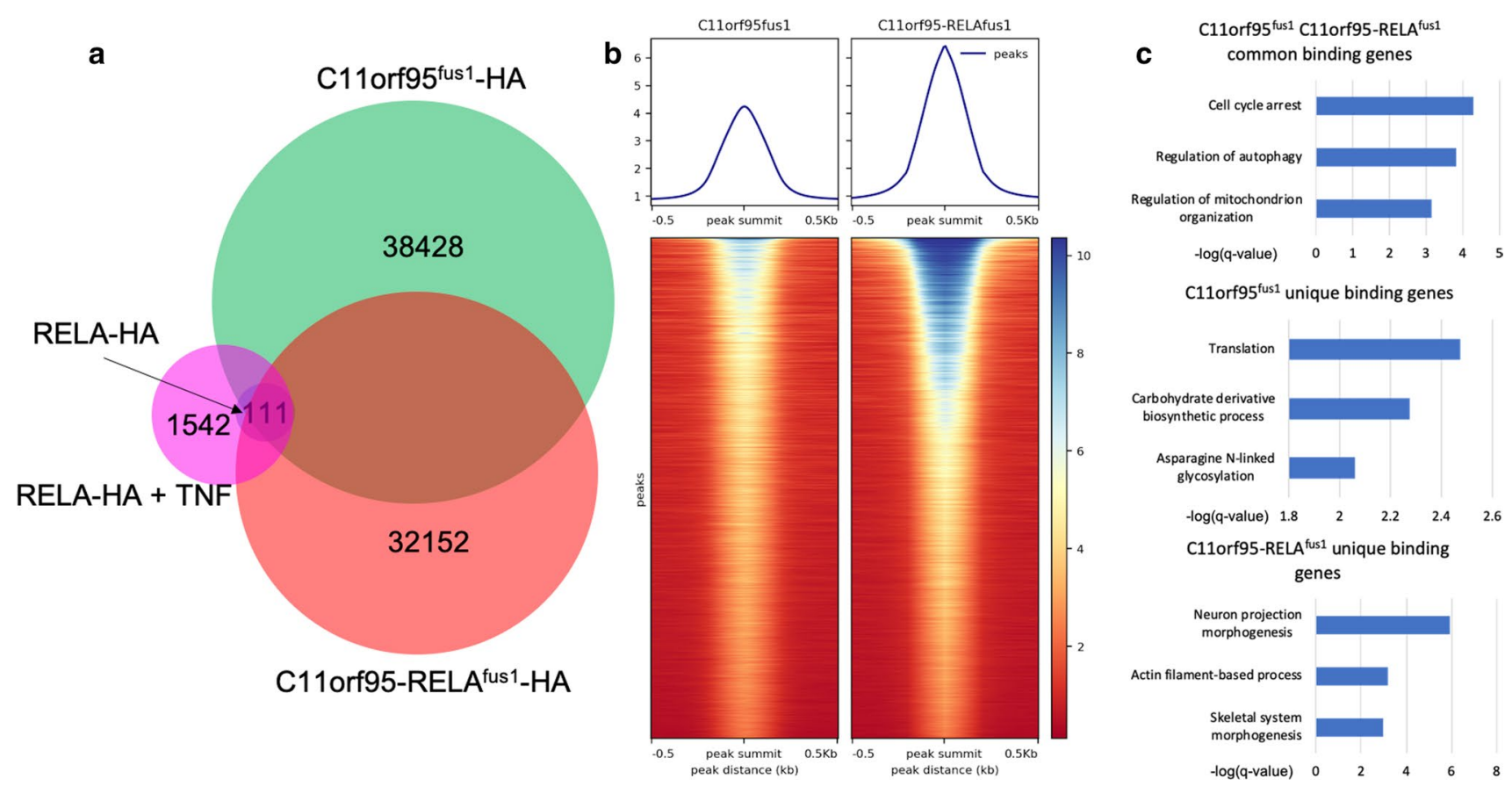

The original article can be found online at https://doi.org/10.1007/ s00401-020-02225-8.

Albert Wu Cheng

albert.cheng@jax.org

$\bowtie$ Ching C. Lau

ching.lau@jax.org

1 The Jackson Laboratory for Genomic Medicine, Farmington, CT, USA

2 Texas Children's Cancer Center, Baylor College of Medicine, Houston, TX, USA

3 Department of Pediatrics, Northwestern University, Chicago, IL, USA
4 The Jackson Laboratory Cancer Center, Bar Harbor, ME, USA

5 Department of Genetics and Genome Sciences, University of Connecticut Health Center, Farmington, CT, USA

6 Institute for Systems Genomics, University of Connecticut Health Center, Farmington, CT, USA

7 Division of Hematology-Oncology, Connecticut Children's Medical Center, Hartford, CT, USA

8 Department of Pediatrics, University of Connecticut Health Center, Farmington, CT, USA 
Publisher's Note Springer Nature remains neutral with regard to jurisdictional claims in published maps and institutional affiliations. 